\title{
Incremental predictive value of carotid intima-media thickness to arterial stiffness for impaired coronary flow reserve in untreated hypertensives
}

Stavros Tzortzis, Ignatios Ikonomidis, John Lekakis, Costas Papadopoulos, Helen Triantafyllidi, John Parissis, Paraskevi Trivilou, Ioannis Paraskevaidis, Maria Anastasiou-Nana and DT Kremastinos

Coronary microcirculation is disturbed in patients with arterial hypertension. Carotid intima-media thickness (IMT) and arterial stiffness are markers of subclinical atherosclerosis with prognostic significance. We investigated whether the combination of increased carotid IMT and arterial stiffness has a greater predictive value for the presence of impaired coronary flow reserve (CFR) than each index alone in never-treated hypertensives. We studied 110 untreated patients (age: $54.5 \pm 12$ years) with newly diagnosed arterial hypertension. We measured (1) carotid-to-femoral artery pulse wave velocity (PWV), (2) carotid IMT and (3) CFR by means of color-guided Doppler echocardiography after adenosine infusion. Among other confounders, arterial stiffness and IMT were independent determinants of CFR (coefficient $B=-0.146$ and $B=-0.006, P<0.05$ ). Arterial stiffness and IMT had an incremental value for the determination of CFR when added to a model including other confounders ( $\chi^{2}$ change $=4.423, P$ for change $=0.038$ after addition of IMT; and $\chi^{2}$ change $=5.369, P$ for change $=0.020$ after addition of PWV). Receiver operating curve analysis showed that PWV $>10.2 \mathrm{~m} \mathrm{~s}^{-1}$ and IMT $>1 \mathrm{~mm}$ were the optimal cutoff values to predict a CFR $<2.5$. Patients with IMT $>1 \mathrm{~mm}, \mathrm{PWV}>10.2 \mathrm{~m} \mathrm{~s}^{-1}$ or their combination had an odds ratio of $3.5,5.0$ and 11.2, $P<0.05$, for a CFR $<2.5$, respectively. The combination of increased carotid IMT and arterial stiffness has a greater predictive value for impaired CFR than each index alone in never-treated hypertensives.

Hypertension Research (2010) 33, 367-373; doi:10.1038/hr.2010.2; published online 5 February 2010

Keywords: coronary flow reserve; intima-media thickness; pulse wave velocity

\section{INTRODUCTION}

Hypertension is a major risk factor for cardiovascular disease ${ }^{1}$ and is associated with functional and structural arterial wall changes. These changes are best reflected by arterial stiffness and carotid intimamedia thickness (IMT). Increased arterial stiffness is associated with cardiovascular mortality in patients with essential hypertension and is accurately assessed by measuring the carotid-to-femoral pulse wave velocity (PWV). ${ }^{2,3}$ In hypertensive patients, IMT is usually found to be increased, reflecting a generalized vascular damage. ${ }^{4,5}$

Coronary microcirculation is disturbed in patients with essential hypertension and is reliably assessed by calculating the coronary flow reserve (CFR) after adenosine-induced hyperemia using Doppler echocardiography. ${ }^{6,7}$ Changes in CFR may reflect early abnormalities of coronary microcirculation in the context of a generalized vascular damage in hypertensive patients. ${ }^{6}$

In our previous studies, we have demonstrated that, in hypertensive patients, impaired CFR was related to increased PWV. ${ }^{8}$ Other investigators have shown an association between IMT and CFR. ${ }^{9}$ The assessment of CFR provides important clinical and prognostic information in hypertensive patients. ${ }^{10-14}$ However, its measurement requires specialized medical staff and dedicated echocardiographic equipment, which is not readily available in each hospital. Conversely, IMT and PWV are easier to obtain and do not require prolonged training. The complementary value of arterial stiffness and IMT for the determination of impaired coronary microcirculation has not been fully investigated. We hypothesized that PWV, a marker of vascular function, and IMT, a marker of vascular structural abnormalities, have a greater predictive value for the determination of impaired CFR than each index alone.

In this study, we investigated whether IMT and arterial stiffness, as assessed by PWV, are complementary determinants of CFR among other conventional determinants of coronary microcirculation, and whether the combination of increased IMT and PWV has a greater predictive value than each index alone for the presence of impaired CFR in newly diagnosed untreated patients with essential hypertension.

\section{METHODS}

Study population

Among 500 patients attending the Hypertension Unit of our hospital during 2005-2006, 110 never-treated consecutive patients (mean age: $54.5 \pm 12$ years, 
51 females) with newly diagnosed essential hypertension were prospectively studied as outpatients in our echocardiography laboratory. The diagnosis of arterial hypertension was defined as seated systolic blood pressure (SBP) $\geqslant 140 \mathrm{~mm} \mathrm{Hg}$ and/or diastolic blood pressure (DBP) $\geqslant 90 \mathrm{~mm} \mathrm{Hg}$ during at least three measurements and/or $>125 / 80 \mathrm{~mm} \mathrm{Hg}$ during $24 \mathrm{~h}$ ambulatory blood pressure (BP) monitoring. Patients with elevated clinic BP $(\geqslant 140 /$ $90 \mathrm{~mm} \mathrm{Hg})$ and normal $24 \mathrm{~h}$ ambulatory BP recordings $(<125 / 80 \mathrm{~mm} \mathrm{Hg})$ were characterized as white-coat hypertensive and were also excluded from the study.

Exclusion criteria were history of diabetes mellitus or a fasting plasma glucose $>7 \mathrm{nmoll}^{-1}(125 \mathrm{mg}$ per $100 \mathrm{ml})$, familiar dyslipidemia, coronary artery disease and cardiomyopathy, as these factors may directly influence coronary microcirculation, as well as chronic pulmonary disease. All patients underwent a noninvasive test (thallium scintigraphy, dobutamine stress echocardiography) to exclude myocardial ischemia. None of the patients were on treatment with statins or cardioactive medications, and none of the female patients were on hormone replacement treatment.

The study protocol was approved by the Institute's Ethics Committee, and written informed consent was obtained from all patients.

Analyzed risk factors for atherosclerosis included body mass index (BMI), dyslipidemia and smoking. Dyslipidemia was defined as fasting total cholesterol $>5.17 \mathrm{mmoll}^{-1}(200 \mathrm{mg}$ per $100 \mathrm{ml})$ or low-density lipoprotein cholesterol $>3.36 \mathrm{mmoll}^{-1}(130 \mathrm{mg}$ per $100 \mathrm{ml})$, or fasting triglycerides $>2.66 \mathrm{mmoll}^{-1}$ (200 mg per $100 \mathrm{ml})$.

\section{Echocardiography}

Studies were conducted using a Vivid 7 (GE Medical Systems, Horten, Norway) phased array ultrasound system using second harmonic imaging. All studies were digitally stored and were analyzed by two observers blinded to clinical and laboratory data, using a computerized station (Echopac GE, Horten, Norway). All patients had adequate images for analysis.

\section{D, Doppler and color tissue Doppler echocardiography}

From cross-sectional echocardiographic images of the left ventricle (LV), the following measurements were made: fractional shortening and ejection fraction (\%), LV mass (LVM) and LVM index, as well as left atrium dimension (mm), according to previously published methodology. ${ }^{8}$

Flow velocity profiles were obtained using color, pulse-wave Doppler from four chambers apical projection. From the mitral valve diastolic waveform, peak early (E) and atrial (A) flow velocities $\left(\mathrm{cm} \mathrm{s}^{-1}\right)$ of the $\mathrm{LV}$ diastolic filling were measured.

Myocardial velocities were recorded using color tissue Doppler. A $5 \mathrm{~mm}$ sample volume was placed in septal, lateral, inferior and anterior corner of the mitral annulus in the apical four- and two-chamber view to record the early diastolic velocity (Em). The mean value of $\mathrm{Em}$ at these four sites of the annulus was used in the analysis. The ratio of the $\mathrm{E}$ wave of the mitral inflow measured by pulse-wave Doppler to Em was calculated as an index of LV diastolic filling pressures. ${ }^{8} 15$ Inter- and intra-observer variability of $\mathrm{E}$ and Em were 1 and $3 \%$ and 0.5 and $1.7 \%$, respectively.

\section{Coronary flow}

Coronary flow velocity profiles in the left atrium dimension were obtained using color-guided pulse-wave Doppler from long-axis apical projections using a $7-\mathrm{MHz}$ transducer. In 15 patients with a weak resting Doppler signal of coronary flow, an intravenous bolus infusion of $0.3 \mathrm{ml}$ of contrast agent (Sonovue, Bracco, Italy) was used at rest, and a peak adenosine was used to enhance the signal. We measured velocity time integral of the diastolic coronary waveform (VTI-Vd) at rest and after adenosine infusion $\left(140 \mu \mathrm{g} \mathrm{kg}^{-1}\right.$ per min) for $3 \mathrm{~min}$. Measurements from three cardiac cycles were averaged. CFR was calculated as the ratio of hyperemic to resting diastolic velocity time integral according to standard Doppler methodology. ${ }^{8,16}$ Inter- and intra-observer variability of these measurements in our laboratory were $\sim 4$ and $2 \%$, as previously published. ${ }^{8}$

The mean CFR value of our cohort $(<2.5)$ was used for subgroup analysis after previously published cutoff values for impaired CFR in hypertensives. ${ }^{8,10,17}$

\section{Carotid IMT}

IMT was measured in three paired segments of both carotid arteries from a fixed lateral transducer angle using B-mode ultrasound imaging $(7.0-10 \mathrm{MHz}$, linear array transducer) as described previously. ${ }^{18}$ Measurements were made (1) at the level of the common carotid artery (defined as the segment $1 \mathrm{~cm}$ proximal to carotid dilation); (2) at the level of the carotid bulb (defined as the segment between the carotid dilation and carotid flow divider); and (3) at the level of the internal carotid artery (defined as $1 \mathrm{~cm}$-long arterial segment distal to the flow divider) using an automated tracing system (Vivid 7, GE Medical Systems). In each segment, three measurements of the maximal IMT in the far wall were averaged. The average IMT of all six segments was calculated.

\section{Pulse wave velocity}

Carotid-to-femoral PWV was noninvasively determined using the Complior apparatus (Artech Medical, Pantin, France), which allowed a simultaneous pulse wave recording and automatic calculation of PWV with two pressuresensitive transducers: the first positioned proximally at the base of the neck over the common carotid artery and the other, distally, over the right femoral artery. The distance traveled by the pulse wave was obtained from superficial measurements of the distance between the two transducers, and carotid-tofemoral PWV is then calculated as distance/time $\left(\mathrm{m} \mathrm{s}^{-1}\right) .^{2,3}$

\section{BP monitoring}

Clinic SBP and DBP measurements were obtained using mercury cuff sphygmomanometer on the left brachial artery after $5 \mathrm{~min}$ of rest. We calculated pulse pressure $(\mathrm{PP}=\mathrm{SBP}-\mathrm{DBP})$ and mean arterial pressure $(\mathrm{MBP})$ $((2 \times \mathrm{DBP})+\mathrm{SBP}) / 3$. Three measurements $2 \mathrm{~min}$ apart were averaged.

Twenty-four-hour ABPM was carried out on the nondominant arm using the valid recorder TONOPORT V (General Electric Healthcare, Berlin, Germany) as previously published. ${ }^{10}$ Recordings were analyzed to obtain $24 \mathrm{~h}$, average SBP, DBP, MBP, as well as $24 \mathrm{~h}$ PP. All patients had $>75 \%$ of successful readings.

\section{Statistical analysis}

All variables are expressed as mean \pm s.d. Statistical analysis was performed using the SPSS 13.0 statistical software package (SPSS, Chicago, IL, USA). Variables were tested by the Kolmogorov-Smirnov test to assess the normality of distribution. Variables that had a nonnormal distribution were analyzed after transformation into ranks. Simple linear regression was used to investigate the relations between variables.

Multiple linear relations were checked by multiple linear regression analysis using forward or backward procedure. Age, sex, BMI, LVM, atherosclerotic risk factors (clinic or $24 \mathrm{~h} \mathrm{BP}$, smoking, dyslipidemia), as well as E/Em, were forced into the regression analysis model as independent variables, to take into account any possible relationship with the examined dependent variables. Clinic SBP, DBP, MBP and PP, as well as $24 \mathrm{~h}$ SBP, DBP, MBP and PP, were entered into the multivariable model separately to avoid collinearity. Associations are presented by means of correlation coefficient $(B)$ and corresponding 95\% confidence intervals (CIs). All covariates included in the final models were tested for interactions. The tolerance value of each covariate was $>0.5$ in the multivariable models.

To assess the additive value of IMT and PWV over other known determinants of impaired CFR $(<2.5)$, PWV was entered in a second step and IMT in a third step in a multivariable model that included age, sex, BMI, LVM, E/Em, smoke, dyslipidemia and BP parameters, known to impair CFR. BP parameters were entered into the multivariable model separately to avoid collinearity. The $-2 \log$ likelihood ratio of the model before and after inclusion of PWV and IMT, as well as the corresponding $\chi^{2}$ change and the $P$-value of this change, was calculated.

Receiver operating curve analysis was used to determine the optimal cutoff value of PWV for the prediction of reduced CFR $(<2.5$, mean value of hypertensives). Curves were constructed by plotting sensitivity against 1 -specificity. On the basis of these cutoff values, we divided our patients into those with increased PWV $\left(>10.2 \mathrm{~m} \mathrm{~s}^{-1}\right)$ and increased IMT $(>1.0 \mathrm{~mm})$ and into those with lower PWV and/or IMT values to assess the additive value in the determination of CFR. 
Logistic regression analysis was performed to assess the association of CFR $<2.5$ with increased IMT, PWV and their combination. By multivariable analysis, the correlation coefficient $(B)$ and odds ratios with the corresponding 95\% CIs of each one of the increased PWVs, IMTs and their combinations for the determination of $\mathrm{CFR}<2.5$ were calculated after adjusting for age, sex, BMI, LVM, BMI E/Em and risk factors (BP parameters separately, as previously performed)

A $P$-value $<0.05$ was considered to be the level of statistical significance.

\section{RESULTS}

Study population characteristics

Clinical baseline characteristics of the study population are presented in Table 1. All patients had normal ejection fraction.

By receiver operating curve analysis, PWV and IMT predicted a CFR $<2.5$ with area under the curve: $70.1 \%, 95 \%$ CI: $60.3-79.8 \%$, $P<0.001$; and area under the curve: $64.4 \%, 95 \%$ CI: $54.0-74.8 \%$, $P=0.009$, respectively. By receiver operating curve analysis, the optimal cutoff value for the prediction of a CFR $<2.5$ was $>10.2 \mathrm{~m} \mathrm{~s}^{-1}$ for $\mathrm{PWV}$ and $>1.0 \mathrm{~mm}$ for IMT, respectively.

\section{Determinants of coronary flow}

When resting coronary flow was examined, patients with IMT $>1.0 \mathrm{~mm}$ had a higher VTId rest compared with those with IMT $\leqslant 1.0 \mathrm{~mm}$ $(9.61 \pm 2.87$ vs. $8.34 \pm 2.43, P=0.014)$. Similarly, patients with $\mathrm{PWV}>$ $10.2 \mathrm{~cm} \mathrm{~s}^{-1}$ had higher VTId rest compared with those with PWV $\leqslant$ $10.2 \mathrm{~cm} \mathrm{~s}^{-1}(9.55 \pm 2.74$ vs. $8.38 \pm 2.62, P=0.025)$.

In univariate analysis, IMT and PWV, either as continuous or dichotomous variables, were significant determinants of CFR used either as continuous or dichotomous variable (Table 2, $P<0.01)$. The composite of PWV $>10.2 \mathrm{~m} \mathrm{~s}^{-1}$ and IMT $>1.0 \mathrm{~mm}$ was also a significant determinant of CFR (Table 2, $P<0.01$ ).

Furthermore, in univariate analysis for the determination of impaired CFR $(<2.5)$, PWV and IMT were significant determinants of CFR $<2.5(P<0.01)$.

\section{Independent association of PWV and IMT with CFR}

In multivariable regression analysis, PWV and IMT were independent determinants of CFR among age, sex, smoke, dyslipidemia, LVM, BMI, 24h MBP and E/Em (coefficient $B=-0.146,95 \% \mathrm{CI}$ : -0.222 to $-0.070, P<0.001$; and coefficient $B=-0.006,95 \% \mathrm{CI}$ : -0.010 to $-0.002, P=0.040$, respectively). Similar results were obtained after inclusion of each one of the remaining clinic (SBP, DBP and MBP) and $24 \mathrm{~h}$ BP parameters (24h SBP, DBP) in the model separately.

Additive value of IMT to PWV for determination of impaired CFR To assess the additive value of PWV and IMT over other known determinants of impaired CFR, multivariable adjustments were carried out by a stepwise forced-entry approach. The initial model included age, sex, smoking, dyslipidemia, BMI, LVM and E/Em as an index of LV diastolic filling pressure and ambulatory $24 \mathrm{~h} \mathrm{MBP}$. After the addition of IMT, the overall $P$-value was increased to 0.055 , $\chi^{2}$ change $=4.423, P$ for change $=0.035$. After the addition of $\mathrm{PWV}$, the overall $P$-value was further increased to $0.015, \chi^{2}$ change $=5.369, P$ for change $=0.020$. Similar results were obtained if $24 \mathrm{~h} \mathrm{SBP}, 24 \mathrm{~h}$ DBP, and clinic SBP, DBP and MBP were entered into the model instead of ambulatory $24 \mathrm{~h} \mathrm{MBP}$ (Table 3 and Figure 1).

Furthermore, by logistic regression analysis, after adjustment for age, sex, smoking, dyslipidemia, LVM, BMI, E/Em and $24 \mathrm{~h} \mathrm{MBP,}$ patients with increased IMT $(>1.0 \mathrm{~mm})(n=57,51.8 \%)$, increased PWV $\left(>10.2 \mathrm{~m} \mathrm{~s}^{-1}\right)(n=58,52.7 \%)$ and the combination of increased IMT and PWV $\left(>1.0 \mathrm{~mm}\right.$ and $\left.>10.2 \mathrm{~m} \mathrm{~s}^{-1}\right)(n=35,31.8 \%)$ had
Table 1 Clinical characteristics, echocardiographic and vascular measurements of the study population

\begin{tabular}{|c|c|}
\hline Age (years) & $54.5 \pm 12$ \\
\hline Sex (female) & $51(46 \%)$ \\
\hline BMI $\left(\mathrm{kg} \mathrm{m}^{-2}\right)$ & $29.48 \pm 4.05$ \\
\hline Smoking & $30(27 \%)$ \\
\hline Dyslipidemia & $37(33.6 \%)$ \\
\hline $\mathrm{SBP}(\mathrm{mm} \mathrm{Hg})$ & $154 \pm 13.9$ \\
\hline $\mathrm{DBP}(\mathrm{mm} \mathrm{Hg})$ & $91 \pm 9.2$ \\
\hline $\mathrm{PP}(\mathrm{mm} \mathrm{Hg})$ & $60.4 \pm 13$ \\
\hline MBP (mm Hg) & $111 \pm 9.6$ \\
\hline 24-h Mean SBP (mm Hg) & $141.5 \pm 11$ \\
\hline 24-h Mean DBP $(\mathrm{mm} \mathrm{Hg})$ & $91.5 \pm 7.2$ \\
\hline 24-h Mean PP (mm Hg) & $48.8 \pm 10.1$ \\
\hline FS (\%) & $36 \pm 6.9$ \\
\hline $\mathrm{EF}(\%)$ & $69 \pm 7.9$ \\
\hline LVM (g) & $161 \pm 40$ \\
\hline LVMI $\left(\mathrm{g} \mathrm{m}^{-2}\right)$ & $82.2 \pm 17.3$ \\
\hline $\mathrm{LA}(\mathrm{mm})$ & $38.7 \pm 4.7$ \\
\hline LVOT-VTI (cm) & $18.5 \pm 3.5$ \\
\hline $\mathrm{Em}\left(\mathrm{cm} \mathrm{s}^{-1}\right)$ & $10.5 \pm 8.2$ \\
\hline $\mathrm{Em} / \mathrm{Am}$ & $0.95 \pm 0.5$ \\
\hline $\mathrm{E} / \mathrm{Em}$ & $7.85 \pm 3.39$ \\
\hline CFR & $2.51 \pm 0.63$ \\
\hline IMT (mm) & $0.115 \pm 0.033$ \\
\hline $\mathrm{PWV}\left(\mathrm{ms}^{-1}\right)$ & $10.59 \pm 1.96$ \\
\hline
\end{tabular}

Abbreviations: Am, late diastolic velocity of mitral annulus; BMI, body mass index; CFR, coronary flow reserve; DBP, diastolic blood pressure; EF, ejection fraction; Em, early diastolic velocity of mitral annulus; FS, fractional shortening; LA, left atrium; LVM, left ventricular mass; LVMI, left ventricular mass index; LVOT-VTI, left ventricular outflow tract-velocity time integral; IMT, intima-media thickness; MBP, mean blood pressure; PP, pulse pressure; PWV, pulse wave velocity; SBP, systolic blood pressure.

Values are mean \pm s.d.

an adjusted odds ratio of 3.508 (95\% CI: 1.299-9.475), coefficient $B=1.255, P=0.013 ; 4.990$ (95\% CI: 1.618-15.383), coefficient $B=1.607, P=0.005$; and 11.235 (95\% CI: 2.568-49.145), coefficient $B=2.419, P=0.001$, for a CFR $<2.5$, respectively. Similar results were obtained if $24 \mathrm{~h}$ SBP, $24 \mathrm{~h} \mathrm{DBP}$, and clinic SBP, DBP and MBP were entered into the model instead of ambulatory $24 \mathrm{~h}$ MBP.

\section{DISCUSSION}

In this study, we demonstrated that increased carotid IMT and arterial stiffness are independent and complementary determinants of impaired CFR in never-treated patients with essential hypertension. Furthermore, we have shown for the first time that the combination of functional and structural vascular markers such as PWV and IMT has a greater predictive value for impaired CFR than each index alone.

CFR is a marker of coronary microcirculatory function. Studies have demonstrated that, in the absence of significant epicardial coronary or myocardial pathology, hypertensive patients have reduced CFR compared with healthy controls. ${ }^{6,8}$ CFR impairment is observed at early stages of essential hypertension ${ }^{19}$ and in patients with prehypertension. ${ }^{7}$ In these patients, impaired CFR is an indicator of early functional and structural alterations in coronary microcirculation caused by endothelial dysfunction, ${ }^{19,20}$ as well as structural remodeling of intramyocardial arterioles and accumulation of fibrillar collagen. ${ }^{21}$

Arterial stiffness is determined by the visco-elastic properties of the artery. ${ }^{22,23}$ In hypertensive patients, the presence of vascular structural changes, such as hypertrophy and changes in extracellular matrix ${ }^{24}$ and impairment of the endothelium-derived nitric oxide pathway ${ }^{25}$ are related to arterial stiffening. Increased arterial stiffness shifts 
Table 2 Univariate analysis of the determinants of coronary flow reserve in hypertensive patients

\begin{tabular}{|c|c|c|c|c|c|c|}
\hline & \multicolumn{3}{|c|}{ For CFR (as a continuous variable) } & \multicolumn{3}{|c|}{ For impaired CFR ( $<2.5$, as a dichotomous variable) } \\
\hline & $b$ & $95 \% \mathrm{Cl}$ & P-value & B & Hazard ratio $(95 \% \mathrm{Cl})$ & P-value \\
\hline Sex & 0.063 & $-0.162-0.320$ & 0.516 & -0.084 & $0.920(0.434-1.947)$ & 0.827 \\
\hline BMI $\left(\mathrm{kg} \mathrm{m}^{-2}\right)$ & 0.237 & $0.008-0.066$ & 0.012 & -0.083 & $0.920(0.835-1.014)$ & 0.093 \\
\hline LV mass & 0.106 & $-0.001-0.005$ & 0.271 & 0.000 & $1.000(0.991-1.010)$ & 0.924 \\
\hline $\mathrm{MBP}(\mathrm{mm} \mathrm{Hg})$ & -0.136 & $-0.017-0.003$ & 0.156 & 0.025 & $1.026(0.992-1.060)$ & 0.136 \\
\hline $\mathrm{SBP}(\mathrm{mm} \mathrm{Hg})$ & -0.146 & $-0.012-0.001$ & 0.127 & 0.007 & $1.007(0.986-1.029)$ & 0.511 \\
\hline $\mathrm{DBP}(\mathrm{mm} \mathrm{Hg})$ & -0.100 & $-0.017-0.005$ & 0.297 & 0.036 & $1.036(0.999-1.076)$ & 0.059 \\
\hline $\mathrm{PP}(\mathrm{mm} \mathrm{Hg})$ & -0.114 & $-0.014-0.003$ & 0.235 & 0.025 & $1.026(0.992-1.060)$ & 0.136 \\
\hline 24-h SBP (mm Hg) & -0.134 & $-0.018-0.003$ & 0.164 & 0.030 & $1.030(0.996-1.066)$ & 0.087 \\
\hline 24-h DBP (mm Hg) & -0.112 & $-0.023-0.006$ & 0.247 & 0.055 & $1.057(1.005-1.111)$ & 0.031 \\
\hline IMT (mm) & -0.200 & -0.009 to 0.001 & 0.037 & 0.017 & $1.017(1.004-1.030)$ & 0.010 \\
\hline $\mathrm{PWV}>10.2 \mathrm{~m} \mathrm{~s}^{-1}$ & -0.388 & -0.712 to -0.268 & $<0.001$ & 1.355 & $3.877(1.756-8.559)$ & 0.001 \\
\hline $\mathrm{IMT}>1.0 \mathrm{~mm}$ & -0.292 & -0.599 to -0.138 & 0.002 & 1.116 & $3.052(1.403-6.642)$ & 0.005 \\
\hline $\mathrm{PWV}>10.2 \mathrm{~m} \mathrm{~s}^{-1}$ and $\mathrm{IMT}>1.0 \mathrm{~mm}$ & -0.369 & -0.739 to -0.259 & $<0.001$ & 1.848 & $6.345(2.455-16.401)$ & $<0.001$ \\
\hline
\end{tabular}

Abbreviations: BMI, body mass index; CFR, coronary flow reserve; Cl, confidence interval; DBP, diastolic blood pressure; Em, early diastolic velocity of mitral annulus; IMT, intima-media thickness; LV, left ventricle; MBP, mean blood pressure; PP, pulse pressure; PWV, pulse wave velocity; SBP, systolic blood pressure.

$B$ indicates unstandardized coefficient $B$, and $b$ represents standardized coefficient, $\beta$.

pressure wave reflections from diastole to systole, causing (1) augmentation of the systolic aortic pressure and thus increases in LV afterload and wall stress, leading to increased LVM and myocardial oxygen demands and (2) reduction in diastolic aortic pressure resulting in reduced myocardial perfusion. ${ }^{22,23}$ In addition, a stiff aorta has a diminished capacity to serve as a blood reservoir during cardiac ejection, such that blood is available for coronary perfusion during diastole. $^{22}$ Thus, arterial stiffness causes a mismatch between myocardial oxygen demands and myocardial perfusion resulting in subendocardial ischemia, LV diastolic dysfunction and elevation of diastolic filling pressure, which further decreases myocardial perfusion. ${ }^{22}$ Indeed, experimental studies have shown that arterial stiffness contributed to a decrease in $\mathrm{CFR}^{26}$ and has an effect on subendocardial ischemia. ${ }^{27}$ Furthermore, Kingwell et al. ${ }^{28}$ demonstrated that aortic stiffness is an important independent determinant of myocardial ischemic threshold in patients with CAD. In this study, patients with $\mathrm{PWV}>10.2$ had an increased coronary flow at rest and a decreased CFR after adenosine infusion compared with those with PWV $<10.2$. Thus, increased arterial stiffness may have contributed substantially to the changes in coronary flow at rest and after adenosine, as observed in this study.

Carotid IMT can detect morphological changes of the carotid artery, consisting of both an intimal atherosclerotic process and medial hypertrophy. ${ }^{29}$ Increased IMT correlates with most conventional cardiovascular risk factors, ${ }^{30}$ with atherosclerotic lesions in other sites of the arterial tree, ${ }^{31}$ as well as with the presence and severity of coronary artery disease ${ }^{32}$ and endothelial dysfunction in patients with atherosclerosis. ${ }^{33}$ Thus, it may be used as a cumulative vascular marker of the atherogenetic process, reflecting vascular structural changes of the arterial wall.

In this study, we have hypothesized that PWV, a marker of vascular function, and IMT, a marker of vascular structural abnormalities, have a greater predictive value for the determination of impaired CFR than each index alone. Indeed, we have demonstrated that increased IMT and PWV are complementary determinants of impaired CFR after adjustment for several confounders. Moreover, the combination of PWV $>10.2 \mathrm{~m} \mathrm{~s}^{-1}$ and IMT $>1 \mathrm{~mm}$ showed a greater odds ratio for the prediction of $\mathrm{CFR}<2.5$ than each index alone. Previous studies have defined a CFR $<2$ as significantly abnormal, between 2 and 2.5 as borderline normal and $>2.5$ as normal. ${ }^{17,34}$ However, several studies in hypertensives, HOCM, DCM and syndrome X have shown that CFR values of 2.0-2.5 may reflect microcirculatory dysfunction. ${ }^{6,17}$ Thus, the findings of this study suggest that the combination of vascular markers that reflect functional and/or structural changes of the arterial wall has a greater value for the prediction of coronary microcirculatory dysfunction than each index alone.

CFR, carotid IMT and PWV evaluate different aspects of atherosclerosis, as well as different sites of the artery. However, atherosclerosis undergoes systemic progression that affects all vascular territories, causing functional and anatomical changes, and results in the worsening of these atherosclerotic parameters to a different extent. Nevertheless, the functional changes of atherosclerosis show a strong correlation with structural changes. ${ }^{4}$ Thus, the association between increased PWV, increased IMT and impaired coronary microcirculation may be a parallel effect of endothelial dysfunction, fibrosis and structural remodeling in the context of a generalized vascular damage, which is already observed in the early phases of hypertension. ${ }^{21,25,29}$

The findings of our study about the predictive value of the combination of PWV and IMT for the prediction of an abnormal CFR are of clinical significance, as studies have shown that impaired CFR contributes to exercise-induced myocardial ischemia ${ }^{11}$ and LV diastolic ${ }^{12}$ and systolic dysfunction ${ }^{10}$ in hypertensive patients. Furthermore, impairment of CFR seems to account for the poor prognosis of hypertensive patients, especially those with LV hypertrophy. ${ }^{13,14}$ On 


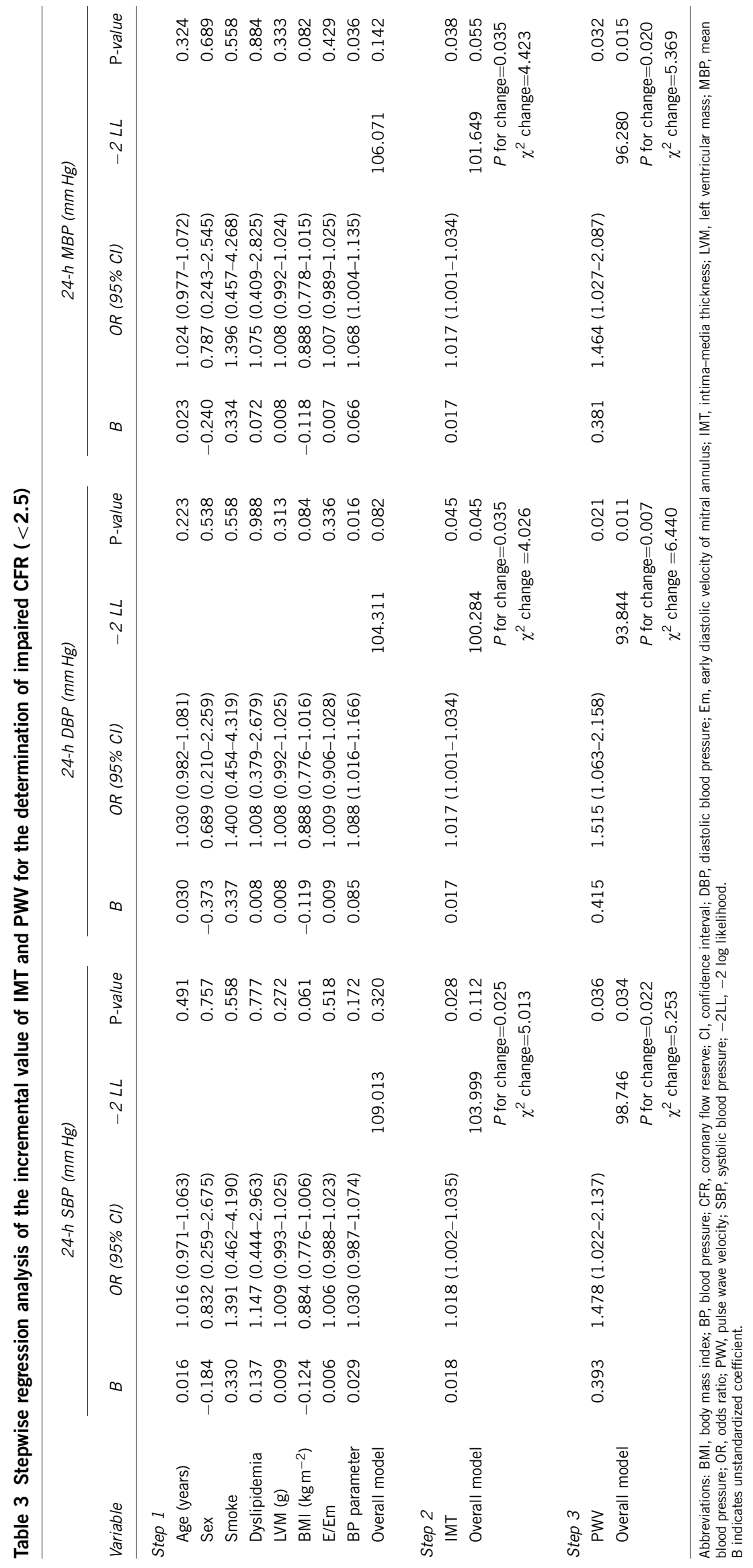




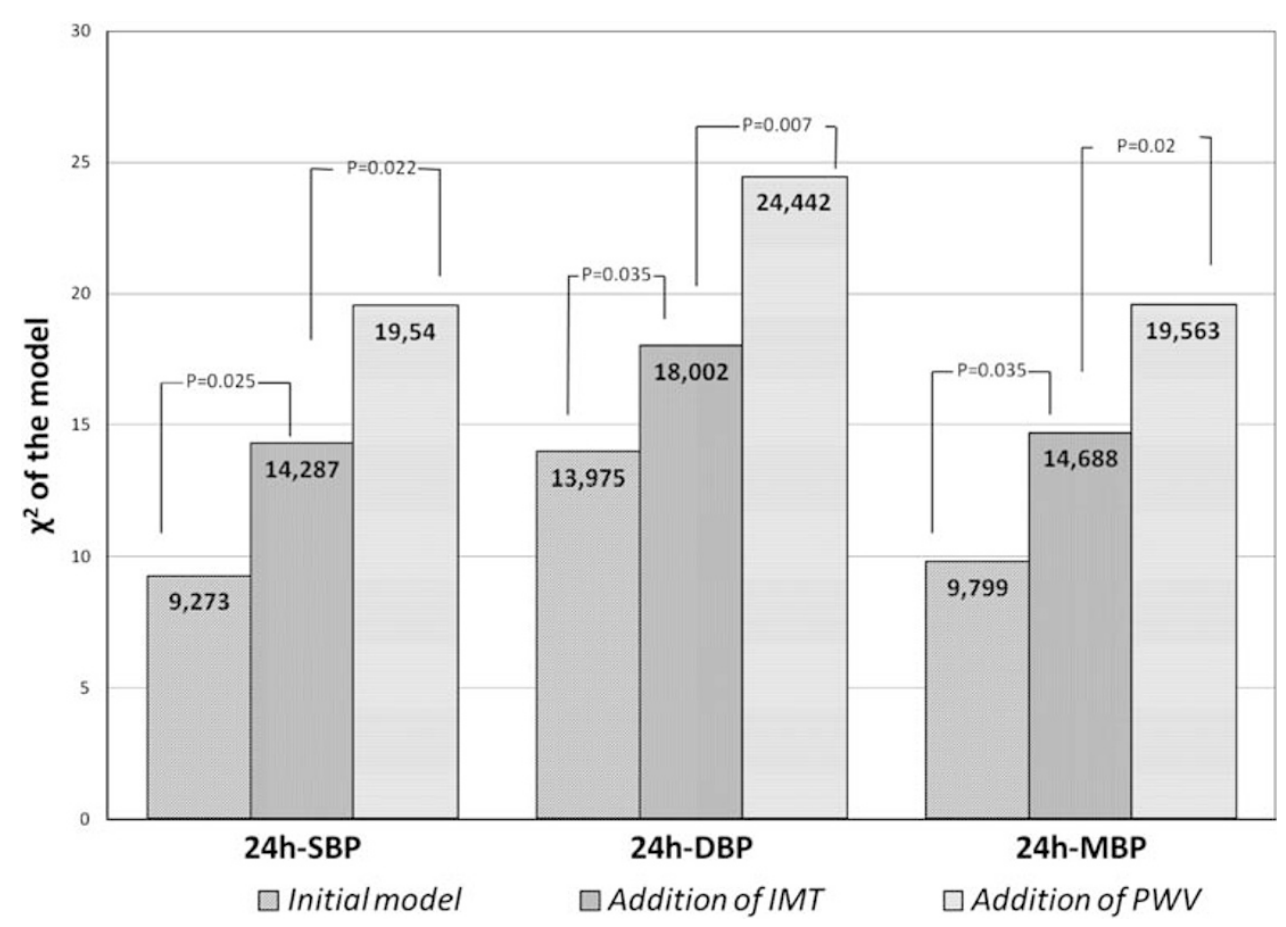

Figure 1 Additive value of carotid intima-media thickness (IMT) and pulse wave velocity (PWV) over other known determinants of impaired coronary flow reserve (CFR) (<2.5). PWV was entered in a second step and IMT in a third step in a multivariable model that included age, sex, body mass index, left ventricular (LV) mass, E/Em, smoking status, dyslipidemia and each $24 \mathrm{~h}$ blood pressure parameter separately (systolic, diastolic and pulse pressure). The $\chi^{2}$ of each model at every step is represented by bars and the $P$-value for change after addition of PWV and IMT is shown above each step.

the other hand, ultrasound measurement of carotid IMT and determination of aortic PWV are easily and reproducibly measured parameters and the devices for their measurements are readily available in most hospitals. Conversely, determination of CFR requires specific equipment and training, as well as a well-organized echocardiographic department. Thus, a simple noninvasive measurement of PWV and IMT may provide significant clinical information about coronary microcirculatory function, in addition to vascular and LV diastolic function, and consequently about prognosis in hypertensive patients.

\section{Study limitations}

Our results establish a close relationship between increasing PWV, IMT and CFR in hypertensive patients, as well as a complementary role of PWV and IMT for the determination of impaired CFR. However, this study was not designed to verify whether this relationship is causative or secondary to endothelial dysfunction and interstitial fibrosis within the arterial and coronary wall in hypertensive patients.

As our hypertensive patients were newly diagnosed, none had evidence of LV hypertrophy. Thus, we were unable to assess the effects of LV hypertrophy on CFR in our study. However, studies have shown that coronary microcirculatory impairment may occur at very early stages of hypertension in the absence of LV hypertrophy. ${ }^{35}$

In conclusion, PWV and carotid IMT are independent and complementary determinants of impaired coronary microcirculatory function and their combination demonstrates a greater predictive value for coronary microvascular dysfunction than each index alone in never-treated patients with essential hypertension.

\section{CONFLICT OF INTEREST}

The authors declare no conflict of interest.
1 Kannel W, Stokes J. Hypertension as a cardiovascular risk factor. In: Robertson JIS (ed). Handbook of Hypertension: Epidemiology of Hypertension, Vol. 6. Elsevier Science Publishing: Amsterdam, 1985, pp 15-34.

2 Laurent S, Cockcroft J, Van Bortel L, Boutouyrie P, Giannattasio C, Hayoz D, Pannier B, Vlachopoulos C, Wilkinson I, Struijker-Boudier H. Expert consensus document on arterial stiffness: methodological issues and clinical applications. Eur Heart J 2006; 27: 2588-2605.

3 Blacher J, Asmar R, Djane S, London G, Safar M. Aortic pulse wave velocity as a marker of cardiovascular risk in hypertensive patients. Hypertension 1999; 33: 1111-1117.

4 Kobayashi K, Akishita M, Yu W, Hashimoto M, Ohni M, Toba K. Interrelationship between non-invasive measurements of atherosclerosis: flow-mediated dilation of brachial artery, carotid intima-media thickness and pulse wave velocity. Atherosclerosis 2004; 173: 13-18.

5 Chambless L, Heiss G, Folsom A, Rosamond W, Szklo M, Sharrett A, Clegg L. Association of coronary heart disease incidence with carotid arterial wall thickness and major risk factors: the Atherosclerosis Risk in Communities (ARIC) Study, 1987-1993. Am J Epidemiol 1997; 146: 483-494.

6 Bartel T, Yang Y, Muller S, Wenzel R, Baumgart D, Philip R, Erbel T. Noninvasive assessment of microvascular function in arterial hypertension by transthoracic Doppler harmonic echocardiography. J Am Coll Cardiol 2002; 39: 2012-2018.

7 Erdogan D, Yildirim I, Ciftci O, Ozer I, Caliskan M, Gullu H, Muderrisoglu H. Effects of normal blood pressure, prehypertension, and hypertension on coronary microvascular function. Circulation 2007; 115: 593-599.

8 Ikonomidis I, Lekakis J, Papadopoulos C, Triantafyllidi H, Paraskevaidis I, Georgoula G, Tzortzis S, Revela I, Kremastinos DT. Incremental value of pulse wave velocity in the determination of coronary microcirculatory dysfunction in never-treated patients with essential hypertension. Am J Hypertens 2008; 21: 806-813.

9 Takiuchi S, Rakugi H, Fujii H, Kamide K, Horio T, Nakatani S, Kawano Y, Higaki J, Ogihar T. Carotid intima-media thickness is correlated with impairment of coronary flow reserve in hypertensive patients without coronary artery disease. Hypertens Res 2003; 26: 945-951.

10 Kozàkovà $M$, Ferrannini $E$, Palombo $C$. Relation between left ventricular midwall function and coronary vasodilator capacity in arterial hypertension. Hypertension 2003; 42: 528-533.

11 Kozàkovà $\mathrm{M}$, Morrizzo $\mathrm{C}$, Ferrannini $\mathrm{E}$, Palombo $\mathrm{C}$. Coronary vasodilator capacity and exercise-induced myocardial ischemia are related to the pulsatile component of blood pressure in patients with essential hypertension. J Hypertens 2003; 21: 1407-1414.

12 Galderisi M, Cicala S, Caso P, Simone L, D'Errico A, Petrocelli A, Divitiis O. Coronary flow reserve and myocardial diastolic dysfunction in arterial hypertension. Am J Cardiol 2002; 90: 860-864.

13 Devereux R, Roman M. Inter-relationships between hypertension, left ventricular hypertrophy and coronary heart disease. J Hypertens 1993; 11(Suppl): S3-S9. 
14 Sicari R, Rigo F, Cortigiani L, Gherardi S, Galderisi M, Picano E. Additive prognostic value of coronary flow reserve in patients with chest pain syndrome and normal or nearnormaly coronary arteries. Am J Cardiol 2009; 103: 626-631.

15 Nagueh S, Middleton K, Kopelen H, Zoghbi W, Quinones M. Doppler tissue imaging: a noninvasive technique for evaluation of left ventricular relaxation and estimation of filling pressures. J Am Coll Cardiol 1997; 30: 1527-1533.

16 Ahmari SA, Modesto K, Bunch J, Stussy V, Dichak A, Seward J, Pellikka P, Chandrasekaran K. Doppler derived coronary flow reserve during dobutamine stress echocardiography further improves detection of myocardial ischemia. Eur J Echocardiogr 2006; 7: 134-140.

17 Dimitrow P, Galderisi M, Rigo F. The non-invasive documentation of coronary microcirculation impairment: role of transthoracic echocardiography. Cardiovasc Ultrasound 2005; 3: 18-26.

18 Lekakis JP, Ikonomidis I, Protogerou AD, Papaioannou TG, Stamatelopoulos K, Papamichael CM, Mavrikakis ME. Arterial wave reflection is associated with severity of extracoronary atherosclerosis in patients with coronary artery disease. Eur $J$ Cardiovasc Prev Rehabil 2006; 13: 236-242.

19 Palombo C, Kozàkovà M, Magagna A, Bigalli G, Morizzo C, Ghiadoni L, Virdis A, Emdin M, Taddei S, L'Abbate A, Salvetti A. Early impairment of coronary flow reserve and increase in minimum coronary resistance in borderline hypertensive patients. $J$ Hypertens 2000; 18: 453-459.

20 Panza J, Casino P, Kilcoyne C, Quyyumi A. Role of endothelium-derived nitric oxide in the abnormal endothelium-dependent vascular relaxation of patients with essential hypertension. Circulation 1993; 87: 1468-1474.

21 Schwartzkopff B, Motz W, Frenzel H, Vogt M, Knauer S, Srauer BE. Structural and functional alterations of the intramyocardial coronary arterioles in patients with arterial hypertension. Circulation 1993; 88: 993-1003.

22 Nichols W, O'Rourke M. McDonald's Blood Flow in Arteries: Theoretical, Experimental and Clinical Principles, 5th edn. Hodder Arnold: London, 2005, pp 67-93. 193-213, 321-337.

23 Vlachopoulos C, Aznaouridis K, Stefanadis C. Clinical appraisal of arterial stiffness: the Argonauts in front of the Golden Fleece. Heart 2006; 92: 1544-1550.

24 Glagov S, Vito R, Giddens D, Zarins C. Micro-architecture and composition of artery walls: relationships to location, diameter and the distribution of mechanical stress. J Hypertens 1992; 10(Suppl 6): S101-S104.
25 Wilkinson I, Qasem A, McEniery C, Webb D, Avolio A, Cockcroft J. Nitric oxide regulates local arterial distensibility in vivo. Circulation 2002; 105: 213-217.

26 Ohtsuka S, Kakihana M, Watanabe H, Sugishita Y. Chronically decreased aortic distensibility causes deterioration of coronary perfusion during increased left ventricular contraction. J Am Coll Cardiol 1994; 24: 1406-1414.

27 Watanabe H, Ohtsuka S, Kakihana M, Sugishita Y. Coronary circulation in dogs with an experimental decrease in aortic compliance. J Am Coll Cardiol 1993; 21: 1497-1506.

28 Kingwell BA, Waddell TK, Medley TL, Cameron JD, Dart AM. Large artery stiffness predicts ischemic threshold in patients with coronary artery disease. J Am Coll Cardiol 2002; 40: 773-779.

29 Juonala M, Viikari J, Laitinen T, Marniemi J, Helenius H, Rönnemaa T, Raitakari O. Interrelations between brachial endothelial function and carotid intima media thickness in young adults. The Cardiovascular Risk in Young Finns Study. Circulation 2004; 110: 2918-2923.

30 Folsom AR, Eckfeldt JH, Weitzman S, Ma J, Chambless LE, Barnes RW, Cram KB, Hutchinson RG. Relation of carotid artery wall thickness to diabetes mellitus, fasting glucose and insulin, body size, and physical activity: Atherosclerosis Risk in Communities (ARIC) Study investigators. Stroke 1994; 25: 66-73.

31 Bots M, Iglesias del Sol A, Grobbee D. Carotid intima-media thickness measurements in observational and intervention studies. Curr Res Vasc Dis 1998; 3: 274-283.

32 O'Leary D, Polak J, Kronmal R, Manolio T, Burke G, Wolfson S. Carotid intima and media thickness as a risk factor for myocardial infarction and stroke in older subjects. N Engl J Med 1999; 340: 14-22.

33 Hashimoto M, Eto M, Akishita M, Kozaki K, Ako J, lijima K, Kim S, Toba K, Yoshizumi $M$, Ouchi Y. Correlation between flow-mediated vasodilatation of the brachial artery and intima-media thickness in the carotid artery in men. Arterioscler Thromb Vasc Biol 1999; 19: 2795-2800.

34 Gould KL, Lipscomb K, Hamilton GW. Physiologic basis for assessing critical coronary stenosis. Instantaneous flow response and regional distribution during coronary hyperemia as measures of coronary flow reserve. Am J Cardiol 1974; 33: 87-94.

35 Brush JE, Cannon III RO, Schenke WH, Bonow RO, Leon MB, Maron BJ, Ebstein SE. Angina due to microvascular disease in hypertensive patients without left ventricular hypertrophy. N Eng J Med 1988; 319: 1302-1307. 